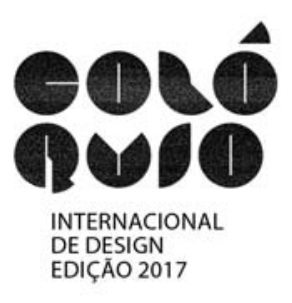

\title{
Design e Interdisciplinaridade: aproximações possíveis com a antropologia
}

\author{
Deborah Camila Viana Cardoso; \\ Wânia Maria de Araújo
}

\section{Resumo:}

Como possui característica interdisciplinar o Design estabelece diálogos com áreas de conhecimento e/ou disciplinas. O presente trabalho, que se constitui como parte do TCC do Curso de Design de Ambientes/UEMG, tem como objetivo apresentar um destes diálogos possíveis: estabelecer conexões entre design e antropologia, especialmente em torno do "fazer design" e "fazer antropologia". A ideia é perceber até que ponto o método antropológico que pressupõe a realização da observação participante e, consequentemente, ver, participar, conversar e escutar o "outro" pode também estar presente no "fazer design". Os projetos de design são desenvolvidos para atender uma diversidade de necessidades provenientes de vários "outros" da nossa ou de sociedades a que não pertencemos. Com efeito, "fazer design", seja na projetação de um ambiente, de um serviço, de um produto implica também neste processo de escutar, conversar, ver e participar do mundo para quem se projeto. Sendo assim, percebe-se nesta prática dos dois campos disciplinares que há pontos de aproximação. Foi daí que surgiu a necessidade de processar esta reflexão. Para tanto, realizou-se uma pesquisa bibliográfica para ressaltar as primeiras considerações em torno da temática. Num primeiro momento o texto se dedica a discorrer sobre o design, suas definições e sua característica interdisciplinar. Em seguida buscou-se uma aproximação da antropologia para dar início aos possíveis diálogos. 0 último tópico aborda o método em design indicando-o como pode estar aí a maior capilaridade para discorrer sobre as aproximações entre disciplinas da área das Ciências Sociais Aplicadas: design e da área das Ciências Sociais: antropologia. Neste momento da pesquisa conclui-se que o campo pra reflexões em torno dos diálogos possíveis entre design e antropologia é fértil e se configura como campo de pesquisa a ser mais explorado.

\section{Palavras-chave:}

Design. Antropologia. Interdisciplinaridade. Método. 


\section{INTRODUÇÃO}

Design e Antropologia são áreas do conhecimento que têm forte relação uma com a outra. A antropologia atravessa a vivência do profissional de Design a todo momento, mesmo que este último não a perceba. Por esse motivo, o tema escolhido para este Trabalho de Conclusão de Curso modalidade monografia - é justamente esse: a relação entre Design e Antropologia e suas possíveis interfaces metodológicas.

Esse tema é relevante para o Design à medida que como área do conhecimento que aceita, para seu crescimento e subsistência, contribuições interdisciplinares, tem relação direta com a Antropologia no que diz respeito aos seres humanos e ao espaço que habitam.

A busca pelo entendimento do ser humano em seu contexto social e territorial é parte importante do trabalho antropológico, assim como também é importante para o fazer Design. Isto porque, na primeira fase da metodologia do Design é realizado o contato com o cliente/usuário e tentase fazer uma imersão em seu mundo para se compreender com exatidão o problema projetual para que a melhor solução possa ser apresentada.

O objetivo deste trabalho é, portanto, partir da perspectiva da interdisciplinaridade do design para traçar paralelos entre o Fazer Design e o Fazer Antropológico, identificando pontos de interseção metodológicos. E isso se dará nas etapas que se seguem:

- Entendimento da definição de Design, sua interdisciplinaridade e sua relação com o método;

- Entendimento da antropologia: seus conceitos e seu objeto de estudo, além da compreensão de seu método de atuação/pesquisa;

- Identificação dos meios pelos quais Design e Antropologia tem, através dos passos metodológicos, de se aproximarem e interagirem;

$\mathrm{O}$ resultado esperado para essa pesquisa é de fato evidenciar a(s) relação(ões) entre as disciplinas por meio dos métodos de "fazer design" e de "fazer antropologia". Desta forma, intenta-se que, de forma consciente, possa o Designer utilizar-se do método antropológico, quando aplicável e pertinente for, para se atingir determinado objetivo ou solução projetual, agregando valor ao trabalho e ao processo cognitivo-criativo do Designer, contribuindo de forma positiva para o alcance dos resultados projetuais e soluções de problemas que mais se aproximem da realidade de seus beneficários.

\section{DESIGN E INTERDISCIPLINARIDADE}

O Design consiste em "um processo estratégico de resolução de problemas que impulsiona a inovação, constrói o sucesso do negócio e leva a uma melhor qualidade de vida através de produtos, sistemas, serviços e experiências inovadores" (WORLD Design Organization - WDO, 2015) ${ }^{1}$.

A multiplicidade de disciplinas que interagem e interpenetram esta área do saber é muito variada, visto que, por definição, é uma profissão transdisciplinar, que "aproveita a criatividade para resolver problemas e co-criar soluções com a intenção de tornar um produto, sistema, serviço, experiência ou um negócio, melhor [...], reformulando os problemas como oportunidades" (WDO, $2015)^{2}$. Anastassakis (2013) define a interdisciplinaridade como uma característica contemporânea das ciências, que faz com que mais de uma área do conhecimento corrobore assertivas de outras, ou seja, faz com que uma proposição seja validada por uma comunidade diferente da de seus pares, o que, segundo a autora, "não é de pequena monta" (ANASTASSAKIS, 2013, p.181).

Essa contemporaneidade da interdisciplinaridade tem relação direta com o fato de o Design estabelecer relações intensas com as questões culturais, socio-políticas e econômicas de um tempo (MOURA, 2011). Em um mundo contemporâneo, novos métodos e metodologias de ensino em Design, ou metodologia de projeto, devem ser propostos com os fins de alcançar os objetivos de produção de bens, serviços e experiências para seres humanos que habitam esse mundo. Moura (2011, p. 4) assinala que vive-se um momento de uma "intensa mudança de paradigmas, intensificadas pela aceleração do tempo e aproximação dos espaços físicos, geopolíticos e culturais", sendo esse momento pertencente à chamada hipermodernidade: um tempo de exageros, que potencializa as possibilidades

\footnotetext{
${ }^{1}$ Tradução livre

${ }^{2}$ Tradução Livre
} 
de comunicação e informação, mas que, ao mesmo tempo, fragiliza o ser humano. Tempo em que uma "cultura-mundo", globalizada, é disseminada, e junto a ela, uma infinidade de problemas globais são trazidos à tona (miséria, imigração, crise econômica...), mas, sobretudo, também problemas existenciais (identidades, crenças, crise dos sentidos, distúrbios de personalidade...).

Viver nesse mundo hipermoderno, exige, de tudo, incluído o Design, e todos, muita flexibilidade. Moura (2011, p. 5), traz a definição de "Contemporâneo em Design" como sendo um refletir sobre

[...] os discursos construídos nas várias relações que se estabelecem na vida e na relação do homem com as atitudes, o modo de vida, os objetos e sistemas das mais diferentes naturezas. Refletir e analisar o ato, o processo e o método de projetar, transformar, inovar tanto os objetos contextualizados quanto os recontextualizados, dando espaço ao inusitado, ao inovador, à inter-relação entre as diferentes disciplinas e campos do conhecimento humano. Pensar o ser humano e as questões relacionadas ao viver, das mais simples às mais complexas. Pensar sobre a história do homem, suas referências e sua capacidade de adaptação e transformação perante as possibilidades midiáticas, interativas, virtuais e imateriais, bem como no objeto material e todo seu entorno (MOURA, 2011, p. 5).

Nesta reflexão (Moura, 2011), aponta para uma complexidade do contemporâneo que engloba, inclusive, a interdisciplinaridade e a transdisciplinaridade.

Na década de 1970, Redig ${ }^{3}$ já pensava o Design como atividade interdisciplinar por natureza e se destacou quando ousou definir os eixos temáticos para o entendimento do Design, eixos estes que deveriam nortear o ensino, pesquisa e extensão relacionados ao Design no Brasil, quais sejam:

- Antropologia;

- Ecologia;

- Economia;

- Ergonomia;

- Percepção e

- Tecnologia (REDIG, 1977, apud BARCELLOS et al, 2015).

Esses eixos temáticos ainda hoje permanecem válidos e muito atuais, visto que a Economia é a base da sociedade, determinando produtos e serviços; a Ergonomia se uniu à Tecnologia para aprimorar a usabilidade daqueles; Tecnologia e Percepção se tornaram parceiras, no contexto de uma sociedade inserida na pós modernidade contagiada pela virtualização do cotidiano; Paradigmas antropológicos mudam todas as vezes que a sociedade passa por alterações (interações, interconexões, comunidades virtuais, composição da cibercultura); o caráter socioambiental do design também ganhou relevância à medida que se uniu à tecnologia para solucionar seus próprios erros de trajeto ecologia (BARCELLOS et al, 2015).

\section{Design e Antropologia: aproximações possíveis}

A Antropologia (anthropos: "homem" ou "humano" e logos: "conhecimento") é uma ciência integradora que estuda o homem no âmbito da sociedade e da cultura a que pertence, combinando perspectivas das ciências naturais, sociais e humanas e que "visa construir um saber sobre o humano, de alcance universal" (AGIER, 2015, p. 10). Ela se debruça sobre a diferença no estudo de grupos e sociedades no intuito de construir interpretações em torno das formas como eles vivem e experimentam o cotidiano. "Fazer antropologia" significa ir ao encontro do outro em seu mundo, fazer o exercício da escuta, observar, participar e conversar, para depois voltar e escrever interpretações sobre este "outro" e seu mundo (MELO, 1997).

"Fazer Design" significa buscar solução para um problema (a forma mais criativa, ou mais estratégica, ou mais eficiente), de maneira a atender às necessidades de um cliente ou usuário de um

\footnotetext{
${ }^{3}$ Designer formado na Escola Superior de Desenho Industrial do Rio de Janeiro - ESDI
} 
determinado sistema, espaço, produto etc., sempre com foco no ser humano. Para isso, é necessário também ouvir, observar, encontrar, conversar para planejar ações.

Resta saber porque, mesmo sendo a antropologia eixo temático para entendimento do Design, esta disciplina se encontra hoje tão distante do Design no ensino universitário, por exemplo. Para Anastassakis (2013) talvez seja um problema da própria Antropologia, que tem, muitas vezes, se afastado da vida prática por vários motivos, dentre eles:

- O fato de acreditar que o pesquisador é um ser neutro, que não deve propor transformações sociais. É o chamado foco do pesquisador no antropocentrismo;

- Acreditar que essas transformações não são de sua responsabilidade, mas responsabilidade de outros profissionais de áreas relativas as artes, arquitetura, design e afins;

- O fato de a disciplina não fazer esforço para se aproximar de outras, fazendo com que nunca seja reinventada e que nunca rompa barreiras consideradas limitantes, como, por exemplo, o já citado foco no antropocentrismo, que impede a assunção do caráter político do trabalho etnográfico e antropológico face às demandas dos grupos com os quais trabalha.

Há hoje uma tendência de aproximação maior entre essas duas disciplinas caracterizada por um aumento das universidades (Escócia, Austrália, Inglaterra) que exploram essa interdisciplinaridade (ANASTASSAKIS, 2013). A aproximação entre Design e Antropologia, ao contrário do que muitos pensam, não significa anular uma disciplina em favor de outra, ou seja, não significa que se pretenda formar antropólogos na Escola de Design ou instrumentalizar estudantes de Design com métodos da antropologia, apenas. Mais do fazer uma "análise antropológica do Design", ou um "Design antropológico", o que se pretende é apostar em uma nova forma de "fazer Design e antropologia, de forma simultânea; é experimentar através da conjugação de seus modos de produção de conhecimento em torno de um compromisso dialógico com as questões que nos cercam a todos" (ANASTASSAKIS, 2013, p. 184). É revelar a sinergia existente entre as duas áreas. Ingold (2013, apud ANASTASSAKIS, 2013, p. 182) propõe "que se experimente desenvolver uma antropologia por meio do Design, onde Design é o processo de pesquisa, em que pesquisadores se conjugam às pessoas, em seus desejos e aspirações, a fim de enriquecer tais vidas, tornando-as mais sustentáveis". Portanto, conclui Anastassakis (2013) que, uma antropologia feita dessa forma deve ser, sobretudo, "experimental e improvisatória. Uma antropologia comprometida com um projeto sustentável". E, dessa forma, não haveria espaço para pensar em uma antropologia restrita a somente "observar e descrever as condições e possibilidades da vida no mundo, furtando-se a um comprometimento mais engajado com a sua transformação". É a própria proposta de restituição da antropologia à vida!

Anastassakis (2013, p. 183) afirma ainda que é indispensável que, junto a essa mudança de paradigma, sejam realizadas também mudanças nos paradigmas educacionais: a chamada "educação da atenção, que se pretende realizar a partir da conjugação entre ensino e pesquisa". Concluindo, a autora assinala que isso só seria possível se se passasse "mais tempo em campo com os alunos, desenvolvendo atividades concretas, do que na sala de aula, discutindo sobre as coisas". Observa-se pois, que, reformular o ensino é essencial para que essa interdisciplinaridade aconteça entre Design e Antropologia, fato que somente é possível com o estímulo ao trabalho de campo nas universidades.

Barcellos et al (2015) realizaram um estudo no qual se propuseram a analisar o quanto a antropologia, enquanto eixo temático do Design, influencia, no Brasil, a pesquisa nesse campo do conhecimento. Para isso, analisaram-se todos os artigos publicados em todas as edições do P\&D Design (Congresso Brasileiro de Pesquisa e Desenvolvimento em Design) no Brasil - desde a primeira edição do P\&D, em 1994, até a última antes da publicação do artigo, em 2014. Verificou-se que, a média de publicações no eixo antropológico foi de aproximadamente 1/4 (um quarto) em nove das onze edições do P\&D, sendo São Paulo e Rio de Janeiro os estados que mais publicaram nesse sentido (totalizam juntos $50 \%$ dos artigos relacionados ao tema). Minas Gerais teve uma tímida participação nessa estatística, sendo responsável por apenas $6 \%$ das publicações nessa área no país.

Os autores justificam essa discrepância em número de publicações, principalmente em relação ao Rio de Janeiro, pois, segundo eles, "o estado foi o primeiro a desenvolver uma base de ensino para o Design, e foi também um dos precursores quanto aos artigos científicos na área" (BARCELLOS et 
$a l, 2015$, p. 536). Fato este que não se justifica dada a pouca quantidade de publicações do estado de Minas Gerais que teve sua Escola de Design, na época FUMA - Fundação Mineira de Artes Aleijadinho, ao contrário do que afirmaram os autores acima citados, criada em 1955, antes mesmo da ESDI - Escola Superior de Desenho Industrial - no Rio de Janeiro, inaugurada em 1963 (DIAS; SAFAR; AVELAR, 2012) Não justifica, mas, pior do que isso, evidencia um afastamento da Escola de Design/ UEMG - Universidade do Estado de Minas Gerais - da pesquisa relacionada a esse Eixo Temático do Design e antropologia, assim como do Ensino Interdisciplinar tão necessário quanto vital ao Design Contemporâneo.

Conforme Moura (2011, p. 11), "é muito estranho falar em interdisciplinaridade quando ainda atuamos com divisões bem delimitadas entre faculdades e departamentos". Segundo a autora isso, a primeira vista, parece ser uma situação "estanque e impeditiva para o exercício interdisciplinar", mas, mesmo dessa forma é possível trabalhar a interdisciplinaridade no ensino de Design, sendo um dos meios o "Ensino por projeto" que seria, como propõe Moura (2011, p. 12), "trabalhar com a proposta de um projeto que envolva todas as disciplinas presentes em um semestre ou período de curso."

Obviamente isso traz desafios, principalmente aos docentes, que teriam de rever os conteúdos das disciplinas a cada proposta de projeto, ou seja, isso implica na flexibilidade do conteúdo curricular, sem perder a essência do conhecimento a ser tratado na disciplina, mas, sim, focando na potencialização da importância da disciplina no currículo do curso. Além disso, exige dos professores formação continuada, que, conforme dispõe Moura (2011), poderia ocorrer com políticas educacionais que incentivassem a formação de grupos de estudo, de pesquisa, a organização de palestras, seminários, encontros e mini-cursos destinados aos docentes com profissionais, professores e pesquisadores convidados que tragam para os professores da universidade discussões de realidades diversas daquelas vivenciadas por eles.

O professor, nesse cenário, passaria a ser um "educador-pesquisador-orientador que supera o trabalho individual em busca da produção coletiva e interage entre os conteúdos trabalhados e o cotidiano, a partir de problematizações e questionamentos" (MOURA, 2011, p. 13). Nesse contexto, não ocorreria apenas a soma de disciplinas, mas o inter-relacionamento de métodos e linguagens.

Outro desafio que impediria a existência dos processos interdisciplinares é a busca do espaço físico perfeito. Moura (2011) afirma que o ideal seria termos salas sem paredes, com recursos multimídia diversos, que pudessem ser ateliê, estúdio, escritório, que tivessem pranchetas individuais, mas também mesas de trabalho coletivas etc. Além de ter vários professores ao mesmo tempo atuando junto àquele grupo para orientar os trabalhos. Mas conclui a autora que, "se a indisponibilidade de espaço físico e recursos financeiros nos impedirem de desenvolver uma proposta interdisciplinar, significa que não estamos prontos para atuar com a interdisciplinaridade" (MOURA, 2011, p. 15).

Neste contexto de entendimento do Design como uma ferramenta interdisciplinar para melhoria da qualidade de vida dos usuários (WDO, 2015), é preciso entender como, de fato, ele se manifesta na prática, na vida das pessoas, para transformar essa realidade em que vivem.

\section{Design e Método}

Bonotto; Linden (2017) afirmam que o Design, para causar impacto na vida das pessoas, impactos sociais, age através da colocação de uma determinada metodologia em prática, ou seja, Design são os próprios "métodos em ação" (p. 199). Conforme Laville e Dionne (1999, p. 11), método é palavra derivada do grego methodos, formado por meta, que significa "para", e hodos, "caminho". Poderia então ser traduzido como "caminho para", ou "prosseguimento" ou "pesquisa". Afirmam os autores que a preocupação com o método para produzir novos conhecimentos em pesquisa é antiga e remonta a Descartes, que a mais de três séculos já escrevia sobre o assunto:

O método são regras precisas e fáceis, a partir da observação exata das quais se terá certeza de nunca tomar um erro por uma verdade, e, sem aí desperdiçar inutilmente as forças de sua mente, mas ampliando seu saber por meio de um contínuo progresso, chegar ao conhecimento verdadeiro de tudo do que se é capaz. (DESCARTES In LAVILLE; DIONNE, 1999, p. 11) 
Percebe-se, claramente, que métodos são essenciais para que determinado conhecimento seja produzido ou posto em prática sem perda de tempo ou desperdício de recursos mentais e materiais. De forma geral, Laville e Dionne (1999, p. 46) dizem que toda pesquisa científica no campo da Ciências Humanas pode ser resumida da seguinte forma:

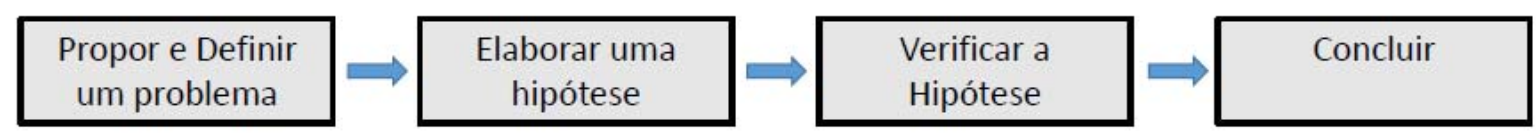

O Design, porém, não pertence ao campo das ciências humanas, mas ao das Ciências Sociais Aplicadas, que nada mais são que ciências, interdisciplinares por natureza, que se dedicam a entender a relação do ser humano com o espaço e realidade social na qual está inserido, agindo prioritariamente de forma a contribuir para a modificação e interação com esse meio social (CININI, 2009). Não poderia, portanto, o Designer, concluir sem agir, com o desejo de transformar e interagir com aquela determinada realidade social. Logo, à metodologia em Ciências Sociais Aplicadas dever-se-ia adicionar uma última etapa, que é a "ação".

Como o meio social é muito dinâmico e está em constante transformação (complexidade do pensamento científico, valores emergentes sobre usuário, cultura, tecnologia, entre outros), a metodologia em Design não deve ter um fim em si mesma, mas deve ser adaptada pelos designers para responder aos problemas que devem ser solucionados em cada projeto (VASCONCELOS, 2009). Portanto, propõe Vasconcelos (2009) que as metodologias, a partir da década de 1990 do século XX, devem retornar à flexibilidade atemporal de suas etapas, não sendo eficiente uma metodologia com fases rígidas em um mundo de transformações tão eminentes e velozes. Mas isso implica, necessariamente, na utilização das metodologias para direcionar os trabalhos multidisciplinares das equipes de Design e, uma vez existindo lacunas metodológicas, por falta de pesquisa sobre o tema, percebe-se que se buscam ferramentas para supri-las visto a impossibilidade de trabalho eficiente sem método em qualquer área do conhecimento, incluindo o Design.

Percebe-se isso no Design Social, pois essa lacuna metodológica se evidencia porque os estudos sistematizados ainda são escassos em torno de como colocar em prática as ações e projetos dos Designers que atuam nessa área. Para suprir essa lacuna, foram lançados por diversas instituições interessadas em transformações sociais, os chamados toolkits (kits de ferramentas), que na falta de estudos mais aprofundados, são uma espécie de metodologia a se seguir para colocar em andamento projetos em Design Social.

Bonotto; Linden (2017, p. 203) assinalam que, mais do que fornecer técnicas para a ação, "os toolkits tratam de dar dicas e incentivar mentalidades de modo a formar o designer ou projetista em uma postura empática, colaborativa e, sobretudo, consciente da complexidade dos problemas sociais e de sua responsabilidade para com eles". Os autores ainda reforçam a ideia de que neles, predomina uma visão humana muito forte, nem sempre diretamente relacionada ao Design, mas, por vezes, próxima às Ciências Sociais, principalmente no que diz respeito ao contato inicial com a comunidade (BONOTTO; LINDEN, 2017), caso em que os métodos etnográficos de pesquisa seriam úteis para entendimento de realidades sociais determinadas (AGIER, 2015).

Um primeiro toolkit citado por Bonotto; Linden (2017) é o Design Centrado no Ser Humano $(\mathrm{DCH})$, toolkit desenvolvido pela IDEO - empresa de inovação criada no Vale do Silício por exalunos de Stanford - e está embasado "em métodos e modelos que enfatizam, comunicam, estimulam e explicitam as características, capacidades e comportamentos inerentes do ser humano permitindo que seus desejos, necessidades e experiências sejam ponto de partida para a projeção de soluções, produtos e serviços" (CAVALCANTI, 2014, p. 3). Ele se preocupa, sobretudo, com a maneira como os indivíduos veem, interpretam e convivem com artefatos, estes entendidos como qualquer coisa que possa ser projetada por um Designer (produtos tangíveis, informações, identidades, marcas, ambientes, entre outros). E, nesse sentido, a atuação do Designer passaria por três etapas que seriam: ouvir, criar e implementar.

Outro toolkit ainda relacionado ao Design Social, criado pela Project H's Design Resolution empresa sem fins lucrativos que conecta o poder do Design às pessoas e lugares que mais precisam dele, em 2009, que visa o uso do Design para um bem maior, no qual os projetos seriam voltados "para pessoas ao invés de clientes, para mudança ao invés do consumo" e determina que o Design é 
reflexo do caráter de quem o faz, além de frisar, que, "melhor que minimizar os impactos negativos, é maximizar os positivos" (BONOTTO; LINDEN, 2017, p. 200). Este toolkit cita, em suas seções, maneiras de mudar a mentalidade dos próprios Designers sobre o Design e seus impactos e, para isso, usa os princípios do Design Social que são os próprios títulos de suas seções: visão empática, cocriação, compartilhamento de informações e conhecimento, melhoras sistemáticas, empoderamento e senso crítico.

Seguindo esse raciocínio, as tecnologias sociais e o empreendedorismo social são formas de materializar o Design Social e esses toolkits, para causar impacto na sociedade envolvida e gerar meio de renda para o Designer que o pratica, uma vez que o Design Social está justamente na interseção entre o socialmente benéfico e o economicamente viável (Ver Figura 1) e as tecnologias sociais são "produtos, técnicas ou metodologias reaplicáveis, desenvolvidas na interação com a comunidade e que representem efetivas soluções de transformação social" (FUNDAÇÃO BANCO DO BRASIL, 2017).

Toolkits também são usados para nortear outras áreas do Design cuja metodologia já é bastante estudada e sistematizada, como no caso do Design Thinking. O DCH é toolkit utilizado para direcionar o Design Thinking em várias situações, visto a proximidade das proposições do Design Thinking com o Design Centrado no Ser Humano em suas macro-etapas: ouvir, criar e implementar. Isso demonstra uma não-rigidez das metodologias em Design, no caso especial do Design Thinking em aceitar contribuições de tudo que possa melhorar seu desempenho (CAVALCANTI, 2014).

A metodologia se torna indispensável para o sucesso ou não de projetos de Design, sendo o trabalho sem metodologia fadado ao fracasso ou, a, no mínimo, desperdício de tempo, recursos mentais e materiais, coisas que valem muito no mundo contemporâneo de velocidade e transformações intensas em que vivemos. E, se o Design pretende exercer sua função de ciência social aplicada, focada na transformação social, deve usar métodos, para tornar sua ação cada vez mais eficiente na interação com os grupos socais aos quais se dedica.

\section{CONSIDERAÇÕE FINAIS}

O design, partilha da peculiaridade contemporânea da ciência: a interdisciplinaridade, e configura-se como campo aberto é fértil para diálogos com outras áreas do conhecimento e outras disciplinas. Neste trabalho, buscou-se evidenciar, a partir do próprio conceito de design, como se mostra aberto ao diálogo interdisciplinar. A própria definição de design destaca a presença e importância da interdisciplinaridade. Diante desta característica que não se circunscreve ao design, visto que é uma característica da ciência contemporânea é que surgiu a motivação para esta pesquisa. Além disso, os cursos de design, na graduação, têm dado pouca ênfase nesta reflexão, pois as disciplinas de práticas projetuais que se voltam, de forma mais específica, ao "fazer design" têm como enfoque lidar mais com as técnicas e processos projetuais mais do que à discussão e reflexão das aproximações metodológicas com outras disciplinas. Diante deste cenário, é que se delineiam as reflexões aqui apresentadas que reforçam a possibilidade de diálogos entre o design e a antropologia por meio das questões metodológicas que perpassam os dois campos.

"Fazer design" é projetar para o outro, "fazer antropologia" é se aventurar no mundo do outro, é fazer traduções de outras culturais com as quais o antropólogo conviveu. O design também se vale destas traduções para projetar para o outro, adentrar culturas, sentidos e significados do mundo do outro, para que possa decifrar o que se constitui como sua(s) necessidade(s). No campo do Design Social já se delineam metodologias, por meio dos tool kits que se valem de técnicas que se aproximam dos percurso metodológico da antropologia ao buscar projetar para grupos sociais e as necessidades por eles apresentadas. De acordo com Nicolau; Nicolau (2013, p. 11) "A atividade do design, essencialmente relacionada ao ato de projetar, não pode ser pensada como uma área estática, com fronteiras definidas. Ela se configura a cada nova necessidade profissional e social". Diante das novas necessidades sociais e profissionais há que se atentar ao fato da atividade de design se abrir aos diálogos com outras disciplinas e seus métodos para que possa expressar também sua característica de abertura ao novo e às mudanças, de não permanecer estático. As constatações de proximidade implicam em uma necessidade de investir em ajustes de projetos pedagógicos dos cursos de design para que estas aproximações se efetivem na prática. Desta forma, o caminho a trilhar neste campo ainda é longo, mas repleto de possibilidades de investigações teóricas e empíricas 


\section{Design and Interdisciplinarity: possible proximities with anthropology}

Abstract: Because of his interdisciplinary characteristic, Design establishes dialogues with areas of knowledge and/or disciplines. This paper, which is part of the Finish Task of the habilitation of Interior Design/ UEMG, aims to present one of these possible dialogues: establish connections between design and anthropology, especially around "make design" and "make anthropology". The idea is to realize how the anthropological method, that includes participant observation and, consequently, to see, participate, talk and listen to the "other" can also be present in the action of "doing design". Design projects are developed to meet a diversity of needs coming from various "others" of ours or from societies we do not belong to. In fact, "designing", whether in the design of an environment, a service, or a product also implies in this process of listening, talking, seeing and participating in the world to whom it is designed. In this way, it is perceived in this practice of the two disciplinary fields that there are points of approximation. It was from this that the need arose to process this reflection. To go father with the reflection, a bibliographical research was carried out to highlight the first considerations around the theme. In the first moment the text is dedicated to discuss the design, its definitions and its interdisciplinary characteristic. Next, an anthropological approach was sought to start the possible dialogues. The last topic deals with the design method, indicating how the greatest capillarity can be there to discuss the approximations between disciplines in the field of Applied Social Sciences: design and the area of Social Sciences: anthropology. At this moment of the research it is concluded that the field for reflections around the possible dialogues between design and anthropology is fertile and is configured as a field of research to be more explored.

Keywords: Design. Anthropology. Interdisciplinarity. Method.

\section{Referências bibliográficas}

AGIER, Michel. Encontros Etnográficos: interação, contexto, comparação. Tradução de Bruno César Cavalcanti e Maria Stela Torres B. Lameiras. Revisão Técnica de Yann Hamonic. São Paulo: Editora Unesp; Alagoas: Edufal, 2015. 100p.

ANASTASSAKIS, Zoy. Laboratório de Design e Antropologia: preâmbulos teóricos e práticos. In: Arcos Design. Rio de Janeiro: PPD ESDI - UERJ. Vol. 7, n. 1, Julho 2013. pp. 178 - 193. Disponível em: < http://www.e-publicacoes.uerj.br/index.php/arcosdesign/article/view/10004 >. Acesso em: 14 maio 2016.

BARCELLOS, E.; PASCHOARELLI, L.; MARCALDI, M.; BOTURA JUNIOR, G. De Redig ao P\&D: a trajetória da abordagem da Antropologia no Design. 4a Conferência Internacional para a Integração do Design, Engenharia e Administração para Inovaç̧ão (IDEMI). Flrianópolis, 2015. Disponível em: < https://www.researchgate.net/publication/282673132_DE_REDIG_AO_PD_A_TRAJETORIA_DA_ABOR DAGEM_DA_ANTROPOLOGIA_NO_DESIGN >. Acesso em: 11 maio 2017.

BONOTTO, Elisa; LINDEN, Júlio Carlos de Souza van der. Toolkits orientados ao Design Social. In: BERNARDES, Maurício Moreira e Silva; LINDEN, Júlio Carlos de Souza van der (Orgs.). Design em Pesquisa - Vol. I. Porto Alegre: Marcavisual, 2017, p. 196-216. Disponível em: < http://www.lume.ufrgs.br/handle/10183/157464 >. Acesso em: 30 maio 2017. 
CARDOSO DE OLIVEIRA, Roberto. O Trabalho de Antropólogo. 2. ed. revista pelo autor. Brasília: Paralelo 15; São Paulo: Editora Unesp, 2000. 220p.

CAVALCANTI, Carolina Magalhães Costa. Design Thinking como metodologia de pesquisa para concepção de um ambiente virtual de aprendizagem centrado no usuário. In: Simpósio Nacional de Educação à Distância - Encontro de Pesquisadores em Educação à Distância - UFSCar, 2014. São Carlos. Anais dos trabalhos SIED:EnPED:2014. p. 1 - 11 . Disponível em: <http://www.siedenped2016.ead.ufscar.br/ojs/index.php/2014/issue/view/3 >. Acesso em: 03 jun. 2017.

CININI, Maria Fernanda. Ciências Sociais Aplicadas: o homem e o espaço, infinitas possibilidades. In: Revista Diversa, Belo Horizonte, 2009, n. 15. Disponível em: <https://www.ufmg.br/diversa/15/index.php?option=com_content\&view=category\&layout=blog\&id=1 5\&Itemid=14 >. Acesso em: 03 jun. 2017.

DIAS, M. Regina Álvares; SAFAR, Giselle Hissa; AVELAR, Johelma Pires; "The historical trajectory of the pioneers of design education in Brazil: ESDI/ UERJ and ED/UEMG", p. 110 - 114 . In: Farias, Priscila Lena; Calvera, Anna; Braga, Marcos da Costa \& Schincariol, Zuleica (Eds.). Design frontiers: territories, concepts, technologies [=ICDHS 2012 - 8th Conference of the International Committee for Design History \& Design Studies]. São Paulo: Blucher, 2012. São Paulo: Blucher, 2014. Disponível em: < http://pdf.blucher.com.br.s3-sa-east1.amazonaws.com/designproceedings/icdhs/icdhs-019.pdf >. Acesso em: 03 jun. 2017.

FUNDAÇÃO BANCO DO BRASIL. Tecnologia Social, 2017. Disponível em: < http://tecnologiasocial.fbb.org.br/tecnologiasocial/o-que-e/tecnologia-social/o-que-e-tecnologiasocial.htm >. Acesso em: 03 jun. 2017.

LAVILLE, Christian; DIONNE, Jean. A Construção do Saber: manual de metodologia da pesquisa em ciências humanas. (Tradução Heloísa Monteiro. Adaptação da Obra: Lana Mara Siman). Porto Alegre: Artmed; Belo Horizonte: Editora UFMG, 1999.

MELLO, Luiz Gonzaga de. Antropologia Cultural: iniciação, teoria e temas. 6. ed. Petrópolis: Vozes, 1997

MOURA, Mônica. Interdisciplinaridades no Design contemporâneo. pp. 1 -20. In: MENEZES, M; PASCHOARELLI, L. C. (Orgs). Metodologias no Design: Inter-Relações. São Paulo: Estação das Letras e Cores, 2011, v. 1, pp. 274 - 290. Disponível em: < http://www.academia.edu/4880345/Interdisciplinaridades_no_Design_Contempor\%C3\%A2neo >. Acesso em: 10 mai 2017

NICOLAU, Raquel Rebouças A.; NICOLAU, Vitor Feitosa. Design, Teoria e Prática. In. NICOLAU, Raquel Rebouças A. (org.) Zoom: design, teoria e prática. João Pessoa: Ideia, 2013. Cap 1, p. 8-19

PAZMINO, Ana Verónica. Uma reflexão sobre Design Social, Eco Design e Design Sustentável. I Simpósio Brasileiro de Design Sustentável. Curitiba, 2007. Disponível em: <http://s3.amazonaws.com/academia.edu.documents/36682232/Uma_reflex_uo_sobre_design....pdf? AWSAccessKeyId $=$ AKIAIWOWYYGZ2Y53UL3A\&Expires $=1494110910 \&$ Signature $=\mathrm{kw} \% 2 \mathrm{Ff} 8 \mathrm{vP} \% 2 \mathrm{BrrsF}$ OmF9b8OoeqH\%2FWy4\%3D\&response-content-

disposition=inline\%3B\%20filename\%3DUma_reflexao_sobre_Design.pdf >. Acesso em: 6 maio 2017.

VACONCELOS, Luis Arthur Leite de. Uma investigação em metodologias de Design. Nov. 2009. 94p. Monografia. Universidade Federal de Pernambuco - UFPE. Recife, Nov. 2009. Disponível em: < http://www.academia.edu/210533/Uma_Investiga\%C3\%A7\%C3\%A3o_em_Metodologias_de_Design >. Acesso em: 03 jun 2017.

WORLD Design Organization (WDO). 2015. Coréia do Sul. Disponível em: < http://wdo.org/about/definition/>. Acesso em: 25 mar. 2017. 